\title{
Physical and chemical pre-treatment of waste paper to increase saccharification by Trichoderma viride cellulase
}

\author{
Mokatse K.M.P. and van Wyk J.P.H.* \\ Department of Pharmacology and Therapeutics, Sefako Makgatho Health Sciences University, South Africa \\ Received: 23/11/2018, Accepted: 21/04/2021, Available online: 20/05/2021 \\ *to whom all correspondence should be addressed: e-mail: bioenergy.res@gmail.com \\ https://doi.org/10.30955/gnj.002964
}

\section{Graphical abstract}

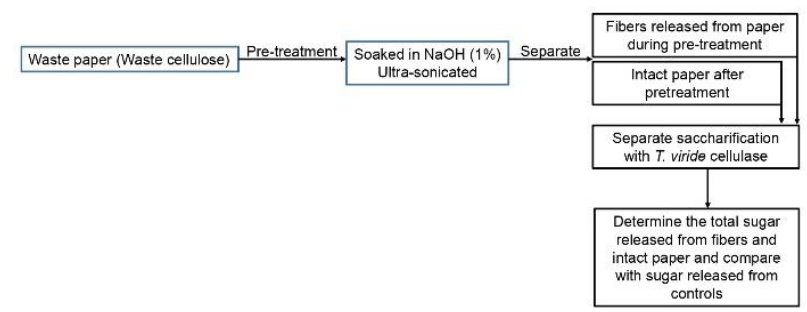

\section{Abstract}

Waste paper is a major component of solid waste with cellulose, a glucose biopolymer, as structural component. Cellulose is a worthy substance with renewable possibilities and if resolved into glucose it could be utilised as a feedstock for fermentation into bioproducts like bioethanol and biopharmaceuticals. The extent of saccharification is an important variable to maximise waste paper as a renewable feedstock. The structural nature of cellulose however prevents an effective bioconversion process and as a result procedures need to be developed making waste cellulose more susceptible for the hydrolytic action of cellulase. Seven different paper materials have been chemically and physically pre-treated prior to cellulase catalysed saccharification with Trichoderma viride cellulase. Non-treated brown envelope paper showed the highest relative degree of saccharification followed by Pick 'n Pay advertising paper from a local retailer and foolscap paper while newspaper resulted in the lowest degree of saccharification. When pre-treated with a combined chemical and physical procedure composed of $\mathrm{NaOH}$ and sonication the bioconversion of brown envelope paper showed the highest degree of degradation followed by foolscap paper and office paper. The highest percentage increase in saccharification due to pre-treatment was observed with office paper while newspaper and Woolworths advertsing showing a decrease in saccharification after pre-treatment.

Keywords: Waste paper, T. viride cellulase, pre-treatment, saccharification, sonication.

\section{Introduction}

The growing global population results in the production of thousands of tons of non-recyclable and recyclable solid waste such as waste paper which in many cases are not effectively managed. (Singh et al., 2011). Also of universal importance is the search and development of alternative and renewable feedstocks to replace the current fossil based substances which negatively effect on the environment is becoming more visible. A major advantage to the environment would be if these issues of managing solid waste and development of renewable energy resources could be addressed simultaneously. Lignocellulose is a common biopolymer in plant materials and an important resource considered for bio-product production (Zhang and Cai, 2008). Lignocellulosic materials such as waste paper, rice straw and sugarcane bagasse are potential renewable resources that can be hydrolyzed and converted into fermentable sugars, which can be used as feedstock for the synthesis of bio-products like ethanol, biomedicines and other biochemicals (Lo et al., 2010). Lignocellulosic biomass contains between $50 \%-80 \%$ of carbohydrates that are polymers of 5 carbon and 6 carbon sugar units (Wingren et al., 2005; Zhang et al., 2009). Most carbohydrates can be processed either chemically or biologically to yield bio-products. The structure of lignocellulosic material is made up of lignin, cellulose and hemicellulose therefore the physicochemical and structural compositions of lignocellulose make it resistant to direct enzymatic hydrolysis of cellulose (Broduer et al., 2011). The aim of cellulose pre-treatment is to alter its structure therefore making it more accessible for enzymatic catalyzed hydrolysis, releasing sugar monomers that could be fermented or chemically converted into bioproducts (Alvira et al., 2010).

A number of methods that could be used for the pretreatment of cellulose include, physical (milling and grinding), chemical (alkali, dilute acid, oxidising agents, and organic solvents), physiochemical (steam pretreatment/autohydrolysis, hydrothermolysis, and wet oxidation) as well as biological pre-treatment (Tayyab et al., 2018). Cellulose is a biochemical substance with a high potential to be developed as a feedstock resource for the synthesis of renewable chemical compounds (Popa, 2018). Waste cellulose is part of organic waste which is a major component of solid waste of which the management is currently a topic of global concern. Landfilling and 
incineration are the most popular means of controlling the huge volumes of solid waste, all producing chemical substances such as methane that are not environmentally friendly (Ngoc and Schnitzer, 2009). Although not popular, the illegal dumping of used paper is behaviour patterns in certain communities a process which is mainly responsible for environmental pollution. Waste paper forms a substantial amount of solid waste with various types of paper contributing to this organic component of solid waste. The important of waste paper as a potential resource for bioenergy development due to the presence of cellulose, as a structural component, has been recognized and investigated by numerous scientists (Qin, et al., 2019). Similar to other cellulose based materials can the degradation of cellulose in paper materials also be performed with a cellulase enzyme of bacterial (Dutta, et. al., 2014) or fungal (Park, et al., 2019) origin. To increase this cellulase catalysed saccharification process waste paper could be exposed to physical or chemical pretreatment procedures such as the sodium hydroxide pretreatment (Wu et.al., 2014) and milling (Dahunsi, 2019). Lately a combinational pre-treatment of cellulose has been introduced where rice straw has been exposed to an ultrasound-assisted alkaline $(\mathrm{NaOH})$ treatment prior cellulase treatment. During this procedure the heat energy dissipated from ultrasonification was used to increase the enzymatic digestibility for sugar formation from cellulose. The porosity and surface area of cellulose was increased when treated with sodium hydroxide thus contribute positively to the total degradation of cellulose ( $\mathrm{Wu}$, et. al., 2017). With newspaper and office paper the most prominent types of waste paper used during bioconversion studies (Botta, et. al., 2016; Wu, et. al., 2014) this investigation had at aim to include a wider range of waste paper types and to conclude whether the combinational pre-treatment would have an effect on the degradation of these cellulose materials when treated with $T$. viride cellulase, the primary enzyme system used during waste cellulose conversion studies in our laboratories. The combinational treatment used during this investigation was a mixture of the paper materials with a $1 \%$ sodium hydroxide solution followed by a ultrasonification. The effect of pre-treatment on these materials was determined by comparing the relative saccharification of each materials as expressed in terms of the amount of sugars produced from each material during the cellulase catalysed degradation.

\section{Material and methods}

\subsection{Preparation of waste paper materials}

The various waste paper materials were prepared as circular discs with a diameter of $6.0 \mathrm{~mm}$ each. Thirty pieces of each paper material were transferred to a test tube with the total mass of each substance determined as follows: brown envelope $(0.0964 \mathrm{~g})$, Pick 'n Pay advertising paper $(0.0383 \mathrm{~g})$, Woolworths advertising paper (0.0585 g), foolscap paper $(0.0464 \mathrm{~g})$, office paper $(0.0654 \mathrm{~g})$, filter paper (0.0554 g) and newspaper (0.0405 g). Pick 'n Pay and Woolworths are two local retailers and paper used for advertising by these companies were used during this investigation.

\subsection{Pre-treatment}

Pieces of waste paper were transferred into $10,0 \mathrm{ml}$ beakers and mixed separately with $5,0 \mathrm{ml}$ of a $\mathrm{NaOH}$ solution at concentration of $1.0 \%(\mathrm{w} / \mathrm{v})$. The content was thoroughly mixed and sonicated for 15, 30 and $60 \mathrm{~min}$, respectively at $50 / 60 \mathrm{~Hz}$ with the controls of the paper materials mixed with $0.05 \mathrm{M}$ Tris buffer $(10 \mathrm{ml}) \mathrm{pH} \mathrm{5,0}$ without any $\mathrm{NaOH}$ solution added, also not sonicated. After the pre-treatment procedures the sodium hydroxide solutions of the samples were neutralised with $32 \% \mathrm{HCl}$. Fibres released from the paper materials during the pretreatment was visible in each experimental beaker. These beakers were left at room temperature for 30 minutes where after the supernatant containing the fibres were removed with a pipette and transferred into clean testtubes. Both the pre-treated paper samples (with the fibres removed) and the fibre mixtures were then centrifuged for $10 \mathrm{~min}$ at $4000 \mathrm{rpm}$. After centrifugation the supernatant was removed from both the paper materials and the fibres with the precipitates incubated with the cellulase enzyme. The control was also treated with $T$. viride cellulase.

\subsection{Enzymatic hydrolysis and sugar analysis}

The precipitates obtained after centrifugation of both the pre-treated paper materials and the fibre mixtures as well as the controls were mixed separately with $0.05 \mathrm{M}$ buffer $\mathrm{pH} 5.0(800 \mu \mathrm{l})$ and $200 \mu \mathrm{l}$ of the T. viride enzyme solution $\left(2,0 \mathrm{mg} \cdot \mathrm{ml}^{-1}\right)$ and incubated at $50^{\circ} \mathrm{C}$ for $2 \mathrm{~h}$. After the incubation period the reaction mixtures were cooled to room temperature and mixed with the DNS reagent $(1,0$ $\mathrm{ml}$ ) according to the method described by Miller (Miller, 1959). The resulting mixtures were heated in a boiling water bath for a period of $10 \mathrm{~min}$, with the resulting colour intensity determined on a spectrophotometer (Shimadzu UV-1800) at $520 \mathrm{~nm}$. A sugar calibration curve was constructed using glucose standards ranging from zero $10.0 \mathrm{mg} \cdot \mathrm{ml}^{-1}$. This calibration curve was used to determine the concentration of the various sugar solutions obtained during the cellulase catalysed degradation of the different paper materials. The total amount of sugars released from the various paper materials was determined by adding the amount of sugars released from the pre-treated paper materials as well as sugars released from paper fibres present in the supernatant.

\section{Results and discussion}

A process with little or no negative impact on the environment should be introduced to deal with especially the organic part of solid waste that could be considered as a resource rather than as waste lacking an effective management process. Cellulose, a glucose based biopolymer and structural component of organic waste such as waste paper is an excellent chemical substance that could be developed as a renewable feedstock for the synthesis of many environmental friendly compounds (van Wyk, 2001; Usmani et. al., 2021). When resolved into glucose, a fermentable sugar, by cellulase enzymes waste cellulose would be a suitable resource to be developed as an alternative and sustainable feedstock for chemical and biochemical synthetic processes. Pre-treatment is an 
important tool for cellulose conversion processes, and is essential to change the structure of cellulosic biomass to make cellulose more available to the enzymes that convert the carbohydrate polymers into fermentable sugars (Mosier et. al., 2005) Figures 1-7 reflect information on the degree of saccharification of various waste paper materials pre-soaked in a $\mathrm{NaOH}$ solution and sonicated for different periods of time followed by saccharification with $T$. viride cellulase, a multi-component enzyme system. Figure 1 reflects information on the release of sugar from office paper showing that the combined effect of sonication in the presence of $\mathrm{NaOH}$ resulted in an increase of sugar formation relative to the control sugar concentration. The amount of sugar released during the various sonication periods did not increase after an incubation period of 15 minutes from either the pre-treated paper or fibres when treated with the cellulase enzyme. The average sugar concentration released from pre-treated paper $\left(5.7 \mathrm{mg} . \mathrm{ml}^{-}\right.$ $\left.{ }^{1}\right)$ and fibres $\left(3.0 \mathrm{mg} \cdot \mathrm{ml}^{-1}\right)$ was produced at an average total amount of $8.7 \mathrm{mg} \cdot \mathrm{ml}^{-1}$. This total amount of sugar obtained from pre-treated office paper and the fibres was $92 \%$ higher than the amount of sugar produced during cellulase treatment of the control material.

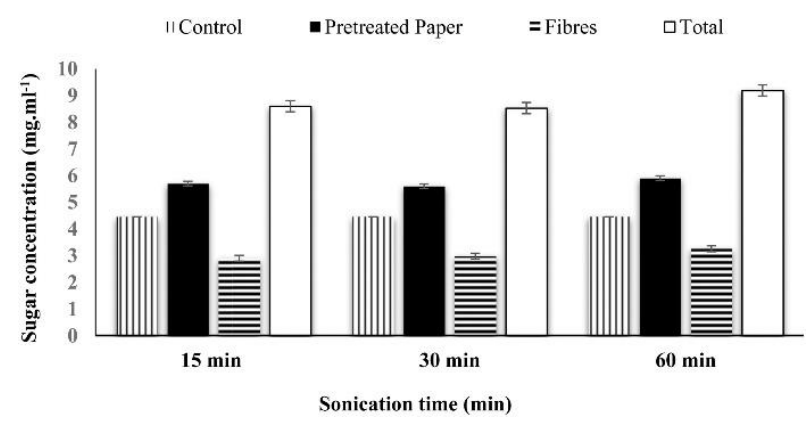

Figure 1. The relative sugar formation from $\mathrm{NaOH}(1 \%)$ soaked office paper and fibres when degraded with $T$. viride cellulase after different sonification periods with the control paper not exposed to any pre-treatment procedure, but degraded by the cellulase enzyme

The observation that sonication time had no increased effect on sugar production during the pre-treatment of office paper was also evident during saccharification of the other pre-treated waste paper materials and their respective fibres. The extent of increase in saccharification of the various waste paper materials due to pre-treatment varied in amount as well as in the sugar concentration released from the control material. During degradation of pre-treated foolscap paper (Figure 2) the average amount of sugar released from this paper material was produced at a concentration of $4.3 \mathrm{mg} \cdot \mathrm{ml}^{-1}$ and $2.4 \mathrm{mg} \cdot \mathrm{ml}^{-1}$ released from the cellulose fibres. The total amount of sugar released from the paper and fibre component was $66 \%$ higher than the sugar concentration of $4.02 \mathrm{mg} \cdot \mathrm{ml}^{-1}$ produced during saccharification of the control material.

During hydrolysis of pre-treated filter paper (Figure 3) with $T$. viride cellulase the control sugar concentration was calculated at an average value of $2.4 \mathrm{mg} \cdot \mathrm{ml}^{-1}$ while the amount of sugar released from paper after pre-treatment resulted in an average sugar concentration of $3.01 \mathrm{mg} \cdot \mathrm{ml}^{-1}$. The average sugar concentration released from cellulose fibres when hydrolysed by $T$. viride cellulase was calculated at $0.49 \mathrm{mg} \cdot \mathrm{ml}^{-1}$. The total amount of sugars obtained during saccharification of this paper and fibre was $45 \%$ higher than the amount of sugar released during the bioconversion of the control material.

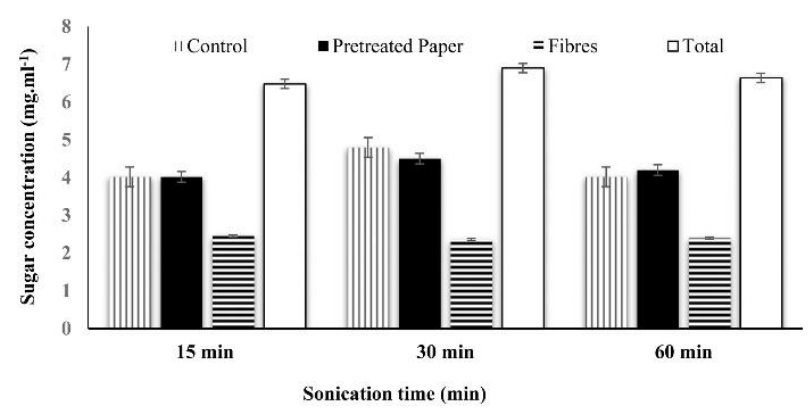

Figure 2. The relative sugar formation from $\mathrm{NaOH}(1 \%)$ soaked foolscap paper and fibres when degraded with $T$. viride cellulase after different sonification periods with the control paper not exposed to any pre-treatment procedure, but degraded by the cellulase enzyme

Figure 4 reflects the amount of sugar released from pretreated brown envelope paper relative to the control degradation. The control sugar concentration obtained from this paper material was calculated at $4.00 \mathrm{mg} \cdot \mathrm{ml}^{-1}$ whilst the amount of sugar released from the pre-treated paper material produced sugar at an average concentration of $2.25 \mathrm{mg} \cdot \mathrm{ml}^{-1}$. The amount of sugar released from this paper material after $60 \mathrm{~min}$ of sonication was slighlty higher than the average concentration of 2.75 $\mathrm{mg} \cdot \mathrm{ml}^{-1}$. Sugars released from the fibres in the supernatant during degradation with $T$. viride cellulase was produced at a concentration higher than the average sugar released during degradation of the pre-treated paper material. This phenomenom was not experienced during saccharification of the other paper materials. The total sugar amount released from pre-treated brown envelope (paper + fibre) was calculated at the concentration of $7.14 \mathrm{mg} \cdot \mathrm{ml}^{-1}$ that was $75 \%$ more than the sugar released as the control value.

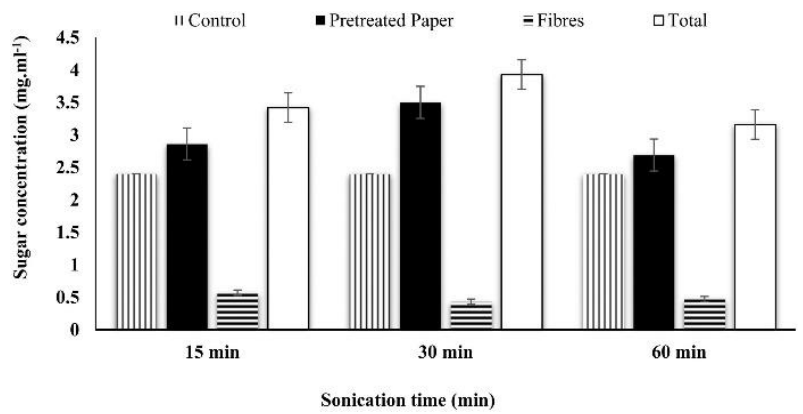

Figure 3. The relative sugar formation from $\mathrm{NaOH}(1 \%)$ soaked filter paper and fibres when degraded with $T$. viride cellulase after different sonification periods with the control paper not exposed to any pre-treatment procedure, but degraded by the cellulase enzyme

Other than the observation from this investigation that $\mathrm{NaOH}$ and sonication pre-treatment resulted in an increase saccharification of paper when treated with $T$. viride cellulase, no increase in bioconversion could be obtained during cellulase catalysed saccharification of pre-treated newspaper (Figure 5). The amount of sugar released from 
the control paper material was higher than the sugar concentration produced by pre-treated newspaper and the paper fibres individually, or the total of these two cellulase treatments. The average amount of sugars released from a control treatment of Pick ' $n$ Pay (Figure 6) resulted in a concentration of $4.47 \mathrm{mg}^{-1} \mathrm{ml}^{-1}$ whilst the average amount of sugar released from the cellulose fibres was calculated at an average concentration of $1.10 \mathrm{mg} \cdot \mathrm{ml}^{-1}$. Sugars released during the cellulase treatment of this pre-treated paper component showed a slighlty increase in released sugar amount during increased sonication periods. The average amount of sugars released from the pre-treated paper was calculated at a concentration of $4.16 \mathrm{mg} \cdot \mathrm{ml}^{-1}$ with the total average sugar released from both incubation procedures at a total of $5.25 \mathrm{mg} \cdot \mathrm{ml}^{-1}$ that was $31 \%$ higher than the average sugar concentration releasd from the control incubation.

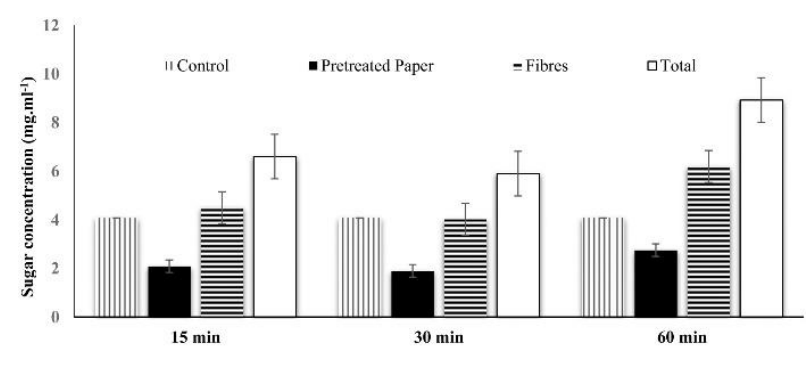

Sonication time (min)

Figure 4. The relative sugar formation from $\mathrm{NaOH}(1 \%)$ soaked brown envelope paper and fibres when degraded with $T$. viride cellulase after different sonification periods with the control

paper not exposed to any pre-treatment procedure, but degraded by the cellulase enzyme

Figure 7 reflects the $T$. viride cellulase catalysed bioconversion of pre-treated Woolworths paper relative to the sugar released from a control incubation. Compared to the other six paper materials the sugar concentration released from Woolworths control paper was the lowest of all paper materials at an average concentration of 0.39 $\mathrm{mg} \cdot \mathrm{ml}^{-1}$. Sugars released from the pre-treated paper component of this material showed an increase from 2.17 $\mathrm{mg} \cdot \mathrm{ml}^{-1}$ after $15 \mathrm{~min}$ of sonication to $4.6 \mathrm{mg} \cdot \mathrm{ml}^{-1}$ after 60 min of sonication with an average value of $3.33 \mathrm{mg} \cdot \mathrm{ml}^{-1}$ sugars released from the cellulose fibres that was produced at an average concentration of $2.35 \mathrm{mg} \cdot \mathrm{ml}^{-1}$ with the average total of both incubations at an average value of 5.8 $\mathrm{mg} \cdot \mathrm{ml}^{-1}$. The relative percentage of sugar released from each paper material before pre-treatment as well as after pre-treatment from fibres and sugar released from the paper precipitate is indicated in Table 1.

The relative percentage saccharification of the various nonpre-treated and pre-treated paper materials is reflected in Table 1. The highest saccharifiaction of non-pre-treated waste paper was obtained during cellulase catalysed degradation of Woolworths advertising paper resulting in $11,1 \%$ sugar formation. This highest yield of sugar formation was followed by a $10.4 \%$ degradation of Pick ' $n$ Pay advertising paper and thirdly a $8.6 \%$ saccharification obtained during the enzymatic treatment of foolscap paper. The lowest degree of bioconversion was obtained from Brown envelope paper at 4,2\% degradation that was 31.5 times less than the amount of sugar released from brown envelope that showed the highest amount of degree of saccharification.

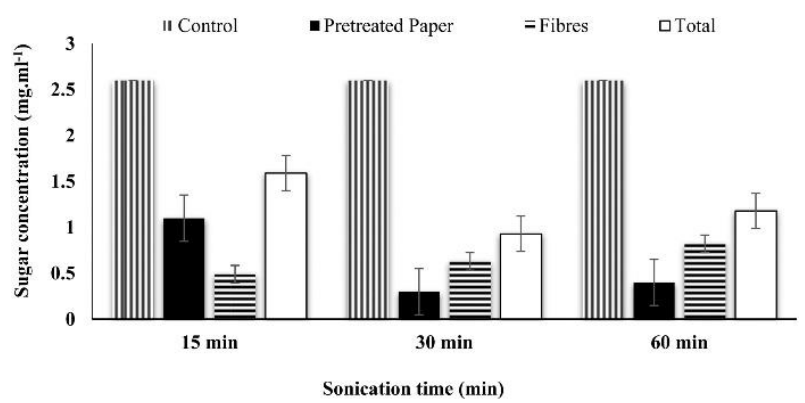

Figure 5. The relative sugar formation from $\mathrm{NaOH}(1 \%)$ soaked newspaper and fibres when degraded with $T$. viride cellulase after different sonification periods with the control paper not exposed to any pre-treatment procedure, but degraded by the cellulase enzyme

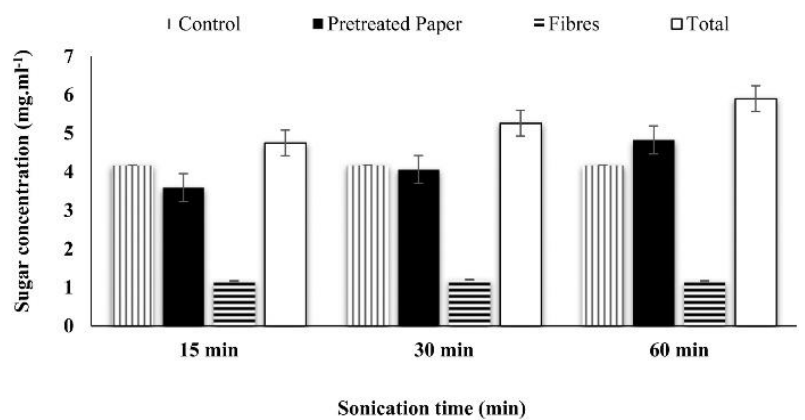

Figure 6. The relative sugar formation from $\mathrm{NaOH}(1 \%)$ soaked Pick ' $n$ Pay advertising paper and fibres when degraded with $T$. viride cellulase after different sonification periods with the control paper not exposed to any pre-treatment procedure, but degraded by the cellulase enzyme

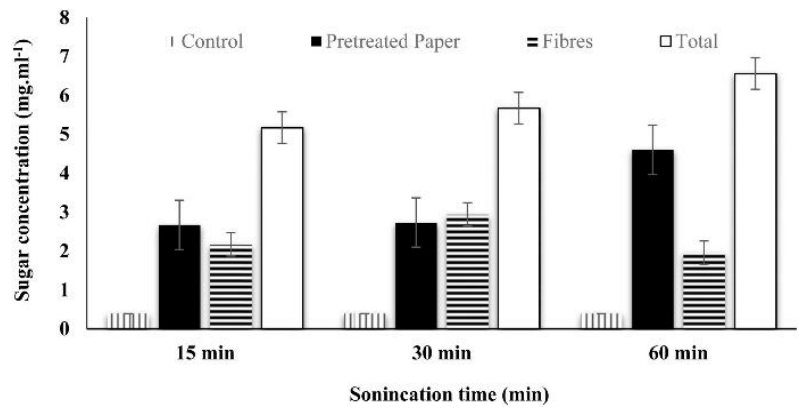

Figure 7. The relative sugar formation from $\mathrm{NaOH}(1 \%)$ soaked Woolworths advertising paper and fibres when degraded with $T$. viride cellulase after different sonification periods with the control paper not exposed to any pre-treatment procedure, but degraded by the cellulase enzyme

During $T$. viride cellulase catalysed bioconversion of the pre-treated materials the highest relative percentage of sugar formation was also obtained from foolscap paper at a percentage value of $14,2 \%$. The second highest relative percentage of sugar formation obtained from the pretreated materials was calculated during degradation of Pick 
'n Pay paper at $13,7 \%$ followed by office paper (13.3\%) and Woolworths advertising paper at a value of $9,9 \%$. The lowest percentage of degradation of pre-treated paper materials was obtained with newspaper at $3.0 \%$. The highest percentage of pre-treated paper degradation was experienced with foolscap paper that was 4,7 times higher than the percentage sugar released from newspaper which produced the lowest relative degree of saccharification.

Table 1: Relative percentage saccharification of different non-pretreated and pretreated waste paper materials during bioconversion with $T$. viride cellulose

\begin{tabular}{|c|c|c|c|c|c|}
\hline Paper material & $\begin{array}{c}\text { Paper mass }(\mathrm{mg}) \\
\text { in an incubation } \\
\text { volume }\left(1 \mathrm{~cm}^{3}\right)\end{array}$ & $\begin{array}{l}\text { Mass }(\mathrm{mg}) \text { of sugar } \\
\text { released from } \\
\text { control paper during } \\
\text { saccharification }\end{array}$ & $\begin{array}{l}\text { Percentage (\%) } \\
\text { saccharification } \\
\text { of control (non- } \\
\text { pre-treated) } \\
\text { material }\end{array}$ & $\begin{array}{l}\text { Total mass (mg) of } \\
\text { sugar released from } \\
\text { the pre-treated } \\
\text { material (fibres } \\
\text { removed) and fibres } \\
\text { (removed from paper) }\end{array}$ & $\begin{array}{c}\text { Percentage (\%) } \\
\text { saccharification of } \\
\text { the pre-treated } \\
\text { material }\end{array}$ \\
\hline $\begin{array}{c}\text { Brown } \\
\text { envelope paper }\end{array}$ & 96,4 & 4,0 & 4,2 & 7,1 & 7,4 \\
\hline Pick'n Pay & 38,3 & 4,0 & 10,4 & 5,2 & 13,7 \\
\hline Woolworths & 58,5 & 6,5 & 11,1 & 5,8 & 9,9 \\
\hline Foolscap & 46,4 & 4,0 & 8,6 & 6,6 & 14,2 \\
\hline Office paper & 65,4 & 4,5 & 6,8 & 8,7 & 13,3 \\
\hline Filter paper & 55,4 & 2,5 & 4,5 & 3,5 & 6,3 \\
\hline Newspaper & 40,5 & 2,6 & 6,4 & 1,2 & 3,0 \\
\hline
\end{tabular}

All the materials were increasingly saccharified by $T$. viride cellulase after the combined chemical and physical pretreatment except for newspaper when the pre-treated material showed a 2.1 times less sugar yield than the control material as well as Woolworths advertising paper when the pre-treated material resulted in a 10,8 times less sugar production. This observation could be the result of the recrystallization of the sugars released during saccharification of these two paper materials. The difference in the extent of saccharification of the various paper materials could have been caused by the difference in content of cellulose, hemicellulose and lignin. If the lignin content in the various paper materials differ the susceptibility of cellulose for cellulase catalysed degradation would also be different thus the amount of sugars released will be less if more lignin is available in a paper material. The structural features of cellulose is also an important variable that could have an effect on the enzyme catalysed degradation of paper materials. If the cellulose component of paper has a higher crystalline nature than amorphous structure the extent of degradation will be less than those paper materials with a higher amorphous cellulose character. The advertising paper are more covered with ink and a glaze substance that could also resist the penetrating effect of the enzyme into the paper material. The structural composition of the Pick 'n Pay and Woolworths paper advertising paper is not described in literature and the current investigation is of the first to investigate the bioconversion potential of these materials.

Waste paper contributes largely to municipal and industrial solid waste even though recycling efforts have been improved during recent years. The rate of recycling waste paper is still low and the shortened fibre length of recycled paper decreases the quality of paper. The maximum ratio of paper-to-paper recycling is $65 \%$ and thus certain sections of paper would always be treated as solid waste (Ikeda et al., 2006). The enzymatic catalysed degradation of waste paper is considered as a green and clean process although the process is relatively slow due to the high crystallinity of cellulose (Ahola, et al., 2008; Lee et al., 2014), the presence of lignin and complexity of the cellulose structure (Walker and Wilson, 1991) as well as the multi-component nature of the cellulase enzyme system (Marais et al., 2012). Pre-treatment is a process that could be applied to render cellulose more susceptible for cellulose catalysed degradation into fermentable sugars which could then serve as a feedstock for bioproduct development.

Environmental conservation, effective waste management procedure and the search and development of alternative energy resources as feedstock for bio-product production would become more topical as the global population is increased like the amount of generated solid waste. Waste paper can only be recycled a number of times before its structural features do not ensure a good quality of paper and it would thus be a good candidate to be developed as a renewable resource addressing the issues of solid waste management and development of renewable feedstock for the synthesis of chemical substances.

\section{Conclusions}

Waste paper is a promising cellulosic substance that could be developed as feedstock for the production of bioethanol and biopharmaceuticals due to the observation that the cellulose component of these materials can be bioconverted with hydrolytic enzymes such as cellulase into glucose a fermentable sugar. Due to crystallinity, a structural feature of cellulose, the cellulase catalysed degradation of cellulose, is relatively slow and the sugar yield obtained from different paper materials varied in yield. A chemical and physical pre-treatment procedure composed of $\mathrm{NaOH}$ soaking and sonication treatment resulted in all papers with the exception of newspaper and Woolworth advertising paper to be increasingly degraded when saccharified with $T$. viride cellulase relative to the degradation of the control incubations. Physical and chemical pre-treatment of most paper materials such as 
brown envelope paper, Pick 'n Pay paper, foolscap paper, office paper and filter paper proved to be effective at increasing the total amount of sugar released during saccharification with $T$. viride cellulase. Sugars released from organic waste materials such as waste paper could thus be utilized as a feedstock for the synthesis of environmental friendly substances and future synthetic procedure will have to rely more on renewable feedstock to protect the environment and preserve natural resources.

\section{References}

Ahola S., Turon X., Osterberg M., Laine J. and Rojas O. (2008), Enzymatic hydrolysis of native cellulose nanofibrils and other cellulose model films: Effect of surface structure. Langmuir, 24, 11592-11599.

Alvira P., Tomas-Pejo E., Ballesteros M., and Negro M.J. (2010), Pretreatment technologies for an efficient bioethanol production process based on enzymatic hydrolysis: A review. Bioresource Technology, 10, 4851-4861.

Botta L.S., Ratti R.P., Sakamoto I.K., Ramos L.R., Silva E.L. and Varesche M.B.A. (2016), Bioconversion of waste office paper to hydrogen using pre-treated rumen fluid inoculum. Bioprocess and Biosystems Engineering, 39, 1887-1897.

Broduer G., Yau E., Badal K., Collier J., Ramachandran K.B. and Ramakrishnan S. (2011), Chemical and physicochemical pretreatment of lignocellulosic biomass: A review. Enzyme Research, 787532.

Dahunsi S.O. (2019), Mechanical pre-treatment of lignocelluloses for enhanced biogas production: methane yield prediction from biomass structural components. Bioresource Technology, 280, 18-26.

Dutta N., Mukhopadhyay A., Dasgupta A.K. and Chakrabarti K. (2014), Improved production of reducing sugars from rixe husk and rice straw using bacterial cellulase and xylanase activated with hydroxyapatite nanoparticles. Bioresource Technology, 153, 269-277.

Ikeda Y., Park E.Y., and Okuda N. (2006), Bioconversion of waste office paper to gluconic acid in a turbine blade reactor by the filamentous fungus Aspergillus niger. Bioresource Technology, 97, 1030-1035.

Lee H.V., Hamid S.K. and Zain S.K. (2014), Conversion of lignocellulosic biomass to nanocellulose: structure and chemical process. Scientific World Journal, ID 631013, 1-20.

Lo C.M., Zhang Q., Callow N.V. and Ju L.K. (2010), Cellulase production by continuous culture of Trichoderma reesei Rut C30 using acid hydrolysate pre-pared to retain more oligosaccharides for induction. Bioresource Technology, 101, 717-723.

Marais S., Barak Y., Lamed R., Wilson D.D., Xu Q., Himmel M.E. and Bayer E.A. (2012), Paradigmatic status of an endo- and exoglucanase and its effect on crystalline cellulose degradation. Biotechnology Biofuels, 5, 1-9.

Miller G.L. (1959), Use of dinitrosalicylic acid reagent for determination of reducing sugars. Analytical. Biochemistry, 31, 426-428.

Mosier N., Wyman C., Dale B., Elander R., Lee Y.Y., Holtzapple M. and Ladish M. (2005), Features of promising technologies for pre-treatment of lignocellulosic biomass. Bioresource Technology, 96, 673-686.
Ngoc U.N. and Schnitzer H. (2009), Sustainable solutions of solid waste management in South East Asian countries. Waste management, 29, 1982-1995.

Park J.Y., Shiroma R., Al-Haq M.I. Zhang Y., Ike M., Arai-Sanoh Y., Ramamoorthy N.K., Sambavi T.R. and Renganathan S. (2019). A study on cellulase production from a mixture of lignocellulosic wastes. Process Biochemistry, 83, 148-158.

Popa V.I. (2018), Biomass as renewable raw material to obtain bio-products of high tech value. Biomass for Fuels and Biomaterials, 1, 1-13.

Singh R.P., Tyagi V.V., Allen T., Ibrahim H.M. and Kothari R. (2011), An overview for exploring the possibilities of energy from municipal solid waste (MSW) in Indian scenario. Renewable and Sustainable Energy Reviews, 15, 47974808.

Tayyab M., Noman A., Islam W., Waheed S., Arafat Y., Ali F., Zaynab M., Lin S., Zhang H. and Lin W. (2018), Bioethanol production from lignocellulosic biomass by environmentfriendly pre-treatment methods: A review. Applied Ecology and Environmental Research, 16, 225-249.

Usmani Z., Sharma M., Awasthi A.K., Sivakumar N., Lukk T., Pecoraro L., Thakur V.K., Robeerts D., Newbold J. and Kupta V.K. (2021), Bioprocessing of waste biomass for sustainable product development and minimizing environmental impact. Bioresource Technology, 322, 124545.

Van Wyk J.P.H. (2001), Biotechnology and the utilization of biowaste as a resource for bioproduct development. Trends in Biotechnology, 19, 172-177.

Walker L.P. and Wilson D.B. (1991), Enzymatic hydrolysis of cellulose: An overview. Bioresource Technology, 36, 3-14.

Wu, F-C., Huang, S-S. and Shih, I-L. (2014), Sequential hydrolysis of waste paper and bioethanol production from the hydrolysate. Bioresource Technology, 167, 159-168.

Qin Y., Li L., Xiao B., Hojo T., Kubota K., Cheng, J and Li, Y-Y (2019), Co-production of biohydrogen and biomethan from food waste and paper waste via recirculated two-phase anaerobic digestion process: Bioenergy yields and metabolic distribution. Bioresource Technology, 276, 325-334.

Wingren A., Galbe M., and Roslander C. (2005), Effect of reduction in yeast and enzyme concentrations in a simultaneoussaccharification-and-fermentation-based bioethanol process. Applied Biochemistry and Biotechnology, 122, 485-499.

Wu F.-C., Huang S.-S. and Shih I.-L. (2014), Sequential hydrolysis of waste newspaper and bioethanol production from the hydrolysate. Bioresource Technology, 167, 159-168.

Wu H., Dai X., Zhou, S.-L., Gan Y.-Y., Xiong Z.-Y., Qin Y.-H., Ma J., Yang L., Wu, Z.-K., Wang T.-L., Wang W.-G. and Wang C.-W. Ultrasound-assisted alkaline pre-treatment for enhancing the enzymatic hydrolysis of rice straw by using the heat energy dissipitated from ultrasonification. Bioresource Technology, 241, 70-74.

Zhang Q.Z. and Chai W. (2009), Enzymatic hydrolysis of alkali pretreated rice straw by Trichoderma reesei ZM4-F3. Biomass and Bioenergy, 32, 1130-1135.

Zhang Y., Pan Z. and Zhang R. (2009), Overview of biomass pretreatment for cellulosic ethanol production. International Journal of Agricultural and Biological Engineering, 2, 51-68. 